\title{
The supply of climate leaders must grow
}

\section{Thomas S. Bateman and Michael E. Mann}

\section{To catalyse climate transformation, we need leadership everywhere. It is time for more of us to take the first steps to lead actively.}

T hrough history, with only occasional exception, progress has been hindered by a much-proclaimed leadership crisis: problems left unsolved, tough challenges going unaddressed, and occupants of powerful positions not delivering. The supply of effective leaders rarely comes close to meeting demand.

In today's climate arena, one striking exception is the Paris Agreement, which showed how collaborative efforts initiated and sustained by many leaders can meet a major need. The agreement emerged because of countless people - and leaders - across many sectors making valuable contributions over many years.

Of course, the work isn't close to being done. The latest international meeting - the 22nd Conference of the Parties (COP 22) to the United Nations

Framework Convention on Climate Change in Marrakech - is now upon us. The presidents of COP 21 and COP 22 tell us ${ }^{1}$ that "our challenge now is to operationalize the Paris Agreement: to turn intended nationally determined contributions into public policies and investment plans for mitigation and adaptation and to deliver on our promises". They describe many needs: to build on the Paris momentum, maintain balanced global involvement and influence, continue working together to strengthen action, support and ambition, and move from a focus on negotiation to a focus on implementation and cooperation. The supply of climate leaders needs to grow to meet these needs.

Here we aim to provide both a leadership nudge and leadership guidance to Nature Climate Change readers.

\section{Box 1 | Leadership challenges for taking Paris forward.}

The summary here reflects the conclusions of the UNFCCC report 'Taking the Paris agreement forward'1. Some key leadership challenges include:

- Advancing four areas: nationally determined contributions; transparency; the global stocktake; and efforts to track progress and promote coordination across bodies.

- Working with a variety of committees, constituted bodies and operating entities to ensure that efforts are undertaken in a balanced manner across bodies and issues.

- Committing to ongoing dialogue and transparency across bodies and towards the wider community.

- Organizing the work between related items within and across bodies, the global stocktake, and arrangements for facilitation and compliance.
- Contributing to the technical examination processes for mitigation and adaptation.

- Engaging in technical expert meetings.

- Leading events and encouraging actions by non-state actors.

- Scaling up and introducing new or strengthened voluntary efforts, initiatives and coalitions.

- Exchanging experiences and best practices on mitigation and adaptation in a holistic and integrated manner.

- Enhancing linkages and creating synergy between, inter alia, mitigation, adaptation, finance, technology transfer and capacity-building.

- Enhancing implementation of training, public awareness, public participation and public access to information, to enhance actions under the agreement.

\section{Climate leadership}

Acts of climate leadership are everywhere. Where global organizations don't act, some countries do. In the United States, where Congress doesn't act, some states do - for example, in a true display of leadership, governors of the west coast states and New England states have banded together into consortia for pricing carbon, representing nearly $30 \%$ of the US population. When governors don't act, local governments and grass-roots organizations might. Coalitions form, and gain power and influence, through individual initiative, purpose-driven dialogue and group action.

To take the Paris agreement forward ${ }^{1}$, we must lead toward more collaborative and integrative work as part of an intensified action agenda, strengthen action on both mitigation and adaptation before 2020, and - before and after 2020 - mobilize finance, technology and capacity-building support. "Taking the Paris agreement forward" ${ }^{\text {indicates just a }}$ few specific tasks requiring leadership and fully engaged 'followership' (see Box 1), all elevated by aspirations that "No issue will be left behind" and "No party should be disadvantaged or excluded"1.

Considering the severity of the climate challenge, our leadership crisis is a specieslevel adaptation failure that individuals and groups must take upon themselves to remedy. Among scientists, every article and every lecture that adds to knowledge and changes how people think is an act of climate leadership. In addition to providing scientific substance, more action-oriented leadership will ask people to change their behaviour in helpful ways.

But motivating people to change their behaviour is a complex challenge, made so by economics, psychology and complicated social-ecological systems ${ }^{2}$. Human systems are unpredictable, nonlinear and interactive, with dynamic relationships 
among system parts, multifaceted issues, differing opinions, and uncertain paths and outcomes. Fortunately, the academic leadership literature now considers open system interdependencies and other complexities. Such systems self-organize, leaders emerge, and structures and processes reform.

Leading in complex living systems ${ }^{3}$ requires a variety of leadership activities including administrating (classic topdown leadership), enabling (clearing the path for others to drive productive change) and adapting to changing environments. Throughout, an essential type of leadership is transcendent, bridging lateral boundaries rather than working downward or upward along hierarchical authority lines. Scientists engage in such leadership when they initiate and sustain interdisciplinary projects and multistakeholder consortia, or engage in politics or other public spheres.

Across all of these activities, two vital characteristics of complexity leadership are its significance (the potential usefulness of new, creative knowledge or adaptive ideas) and its impact (the extent to which other agents embrace and use the new knowledge or idea). These are leadership imperatives because they determine the success and failure of adaptation.

Real leadership - as opposed to inhabiting a position in a hierarchy - is inherently an act of adaptation. In fact, a particular approach to leadership, adaptive leadership ${ }^{4}$, is ideally suited to complex systems. Adaptive leaders think strategically and apply psychological knowledge of decision-making and behaviour change, adding to their own behavioural diversity in ways that enhance their personal effectiveness, as well as enhance systems adaptability and species survival.

However, the costs - psychological and economic - of trying to lead change can discourage attempts to lead in adaptive directions. For example, public outreach and multidisciplinary research are rare among scientists because they are difficult and even discouraged, or at least not supported by many institutions, enough journals, and most tenure and promotion systems. Thus, adaptive leadership often requires swimming against the tide.

So, what drives adaptive change leaders onward? Small wins, deep commitment, doing the right thing, moments of euphoria, example-setting, fun, personal distinction, impact on others, intrinsic motivation, feeling better leading than not, and the ability to achieve some control rather than none. Thus, what we do is not driven solely by reward systems, structural barriers and costs. Anyone who decides to can override those considerations.

Adaptive leaders do not need to know all the answers. They do need to be willing to jump into the pool, try things with an experimental mindset, and learn as they go.

\section{Developing personal leadership}

At the personal level, we suggest some options for moving our own leadership forward.

Face realities. $S h u^{5}$ states unequivocally: "We cannot wait on ignorant, inattentive, or indifferent leaders." We need to provide more and better climate leadership. The longer we wait, the more difficult and expensive climate action will become. Moreover, we lose leverage as time passes.

People are biased towards maintaining the status quo, which adds to the challenge. Doing nothing is the default option, and far more common than taking action. But inaction will not maintain the status quo; it will allow things to worsen. We can preserve the status quo only by leading change now.

Scan for the right opportunities, and take the first step. Be on the lookout for the problem that you would most like to help solve and for the opportunity to participate in new and different ways. The Paris Agreement and Marrakesh provide plenty of options.

Collaborate to compete. Competition characterizes much of society, and science is no exception. Even within the climate change community, rivalries interfere with collaborations and stymie progress. So many barriers hinder interdisciplinary teamwork that even those who give it a try get frustrated and retreat to their silos their own networks or departments. Instead of competing intramurally, why not collaborate to compete against the real foes? Initiating, enabling and sustaining collaborative relationships are truly acts of leadership.

\section{Leave silos and transcend boundaries.} Silo mentality can create counterproductive competitions, and hinder communication, creative thinking and boundary-spanning collaboration ${ }^{6}$. Climate leaders need to talk and forge productive working relationships with people holding differing perspectives, knowledge and interests. Fully engaged scholarship - a participative form of research into complex problems used to obtain the different perspectives of key stakeholders - takes advantage of knowledge that is different, is more penetrating, insightful and actionable, and enables research to truly flourish ${ }^{7}$.

Communicate better. No offence intended! Mobilizing collective action requires effective communication. We need to improve, most importantly when the stakes are high and audience response is inadequate. Scientists must learn to speak in common language and avoid jargon; to familiarize themselves with the lessons of effective communication and work with communication experts; to observe other communicators to see what works and what doesn't; and to learn, often through trial and error, which approaches work best for them. The great climate scientist and climate communicator Stephen Schneider summarized this as "know thy audience, know thy self, know thy stuff."

\section{Adapt and sustain. Setbacks and frustrations are inevitable. Leading change requires not just engagement, but sustained engagement. Conversation is the (potential) building block of constructive change, and conversing effectively is a genuine act of leadership. Get the conversation moving, patiently and persistently and with clear action-oriented purpose.}

Spread best practices. Business leaders are told to always be on the lookout for 'best practices': examples of what works best and what doesn't. To phrase it in the form of a question: do we do enough of this? What are the most helpful forums?

\section{Conclusion}

When a current trajectory needs to change and our leaders are not making that happen, more of us must grab the leadership reins. Sometimes, we have to do it ourselves. As we study complex systems and species adaptation to changing environments, we also must study our own. As individuals and in social groups, we can add useful diversity to our behavioural repertoires by engaging more publicly and collaboratively in ways we have not done before.

Although most academics have deep knowledge of a field, not all have great breadth. You can add professional breadth by crossing scientific 'boundaries', or stretching yourself with new leadership activities, or both. Initiating and sustaining conversations about the possibilities, with current and potential new colleagues, would be true leadership initiatives for a climate that needs them. 
Thomas S. Bateman* is at University of Virginia, McIntire School of Commerce, Rouss Hall and Robertson Hall, Ruppel Drive, Charlottesville, Virginia 22904, USA. Michael E. Mann* is at Pennsylvania State University, Department of Meteorology and Earth and Environmental Systems Institute (EESI), 503 Walker Building, The Pennsylvania University, University Park,
Pennsylvania 16802-5013, USA.

*e-mail: tsb3c@virginia.edu; mann@psu.edu

References

1. Taking the Paris Agreement Forward (UNFCCC, 2016); http://go.nature.com/2fmgT9c

2. Folke, C. et al. Ecol. Soc. 15, 20 (2010).

3. Uhl-Bien, M. \& Marion, R. Complexity Leadership Part I:

Conceptual Foundations (Information Age Publishing, 2008).

4. Heifetz, R., Grashow, A. \& Linsky, M. The Practice of Adaptive
Leadership: Tools and Tactics for Changing Your Organization and the World (Harvard Business Press, 2009).

5. Shu, H. Ethics Int. Affairs 25, 17-26 (2011)

6. Van de Ven, A. H. Engaged Scholarship: A Guide for Organizational and Social Research (Oxford Univ. Press, 2007).

7. Bateman, T. \& Hess, A. Proc. Natl Acad. Sci. USA

112, 3653-3658 (2015).

Published online: 14 November 2016

Corrected after print: 23 November 2016

Urban infrastructure choices structure climate solutions

\author{
Felix Creutzig, Peter Agoston, Jan C. Minx, Josep G. Canadell, Robbie M. Andrew, Corinne Le Quéré, \\ Glen P. Peters, Ayyoob Sharifi, Yoshiki Yamagata and Shobhakar Dhakal
}

\title{
Cities are becoming increasingly important in combatting climate change, but their overall role in global solution pathways remains unclear. Here we suggest structuring urban climate solutions along the use of existing and newly built infrastructures, providing estimates of the mitigation potential.
}

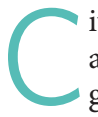

ities and other human settlements are important drivers of greenhouse gas (GHG) emissions, and contribute to mitigation actions world wide ${ }^{1,2}$. At the same time, carbon polluting activities and response measures to these are most tangible where people live and settle. However, the explicit representation of the urbanization process is consistently overlooked in global scenarios depicting solution pathways to mitigation. While urban transport and buildings are captured as part of sectoral approaches, the relevance of urban solutions within the global context remains obscure. This absence is rooted in the limited availability of consistent data, difficulty in synthesizing a heterogeneous body of literature, and reliance on only a few place-specific variables. In addition, global models induce climate mitigation by a generic policy instrument such as carbon pricing. This is inadequate to capture urban solutions, which are set apart by their built environment, and especially by the transport and building components of urban infrastructures. The built environment shapes and structures everyday life of its citizens specifically, and humanity generally. Urban infrastructure provides important boundary conditions - influencing the mitigation potential of energy efficiency improvements or lifestyle changes. Hence, an improved understanding of climate policy solutions hinges on progress in explicitly integrating human settlements in research on global emission pathways, presenting a core challenge for the upcoming sixth assessment cycle of the IPCC where urbanscale mitigation will take centre stage. To make urban solutions analytically accessible, mitigation opportunities need to adequately represent the importance of the built environment in cities worldwide. This would enable a mapping of established policy options on classes of urban infrastructures, demonstrating their importance across spatial scales.

\section{The focal role of urban infrastructures}

For a given level of economic wealth and economic structure, urban infrastructures are central to explaining urban GHG emissions. Evidence suggests that differences in the type and shape of the built environment can result in differences in urban transport and residential GHG emissions by a factor of ten ${ }^{3}$. For example, a low-carbon city typically features: relatively high-density households and population; mixed residential use, workplaces, retail, and leisure activities; a high number of intersections; and mobility choices that avoid excessive construction of lowconnectivity roads ${ }^{1,4}$.

Furthermore, critical boundary conditions for climate change mitigation are determined by urban infrastructure because of its longevity and carbon-intensive nature. Among all long-lived capital stocks, land use, urban form and road systems stand out for their century-long endurance, exceeding the lifetimes of coal power plants and car fleets. This introduces inertia into efforts to modify GHG emission patterns. Additionally the construction of new infrastructure could consume a considerable share of the remaining carbon budget as it is a carbon-intensive process. In fact, these upfront GHG emissions from infrastructure construction explain some of the emissions surge in China during the 2000 s, representing $61 \%$ of emissions growth between 2005 and $2007^{5}$.

Therefore, we suggest that urban climate solutions should be structured along infrastructures, and emissions and associated solutions should be divided into three distinct classes: by use of existing infrastructure; by use of new infrastructure; and by construction of infrastructures. We synthesize published data and calculate order of magnitudes of current and future emissions for each of these three infrastructure classes (Tables 1 and 2).

For existing urban infrastructures, we estimate that their use amounts to approximately $9.6 \mathrm{GtCO}_{2} \mathrm{e}$ annually $(20 \%$ of global anthropogenic GHG emissions), with about $6.8 \mathrm{GtCO}_{2} \mathrm{e}(70 \%)$ from 


\section{Correction}

The Commentary 'The supply of climate leaders must grow' (Nat. Clim. Change http://dx.doi. org/10.1038/nclimate3166; 2016) has been updated to include the authors' initials. The names are correct in the online versions. 